\title{
JM
}

Volume 6 No. 2 (Oktober 2018)

(C) The Author(s)

\section{SURVEI CEPAT : KARAKTERISTIK KEJADIAN ANEMIA \& KEK DI WILAYAH KERJA PUSKESMAS BANGETAYU KOTA SEMARANG TAHUN 2018}

\author{
RAPID SURVEY : CHARACTERISTICS OF ANEMIA \& CED INCIDENT IN \\ WORKING AREAS OF BANGETAYU HEALTH CENTER OF SEMARANG CITY 2018
}

\author{
NENG KURNIATI ${ }^{1}$, SRI RAHAYU ${ }^{2}$ \\ PRODI KEBIDANAN FAKULTAS MIPA, UNIVERSITAS BENGKULU \\ Email: neng.nuha1@gmail.com \\ JURUSAN KEBIDANAN POLTEKKES KEMENKES SEMARANG \\ E-mail : yayoek.1974@gmail.com
}

\begin{abstract}
ABSTRAK
Kurang Gizi pada Ibu Hamil dapat menyebabkan persalinan sulit dan lama, prematur,perdarahansetelahpersalinan,mempengaruhi pertumbuhanjanindandapatmenimbulkan keguguran,cacatbawaan danBeratBayiLahirRendah. Di Provinsi Jawa Tengah Kasus anemia dari tahun ke tahun masih tinggi. Ibu hamil yang mengalami KEK di Puskesmas Bangetayu dari bulan Januari sampai Mei tahun 2018 yaitu sebanyak 73 orang (24,3\%), sementara yang menderita anemia sebanyak 103 orang (34,3\%). Populasi terjangkau dalam penelitian ini adalah ibu hamil yang terdaftar pada poli KIA pada pertengahan bulan Juli hingga menjelang akhir bulan Juli tahun 2018. Sampel diambil secara total insidental selama satu minggu sebanyak 53 orang dan purposive sampling di kelurahan Bangetayu kulon sebanyak 26 orang. Data dikumpulkan melalui quesioner survei cepat epidemiologi gizi dan dari keseluruhan sampel, yang datanya dapat diolah hanya sebanyak 45 quesioner. Dari pengolahan tersebut diperoleh jumlah kejadian anemia (anemia sedang dan ringan) sebesar 71,1\% dan KEK sebesar 28,9\%. Pengetahuan tentang Tablet Tambah Darah 46,7\% baik, tingkat kepatuhan dalam meminum Tablet Tambah Darah 55,6\% tidak patuh, Responden yang menjawab tidak ada anjuran makanan tertentu selama hamil sebanyak $53,3 \%$ dan porsi makan tetap dan lebih sedikit sebanyak $55,6 \%$.
\end{abstract}

Kata Kunci: Survei Cepat, KEK Ibu Hamil, Anemia, Insiden

\begin{abstract}
Malnutrition in Pregnant Women can cause difficult and long-term labor, prematurity, bleeding after childbirth, affect fetal growth and can cause miscarriage, congenital defects, and Low Birth Weight. In Central Java Province Cases of anemia from year to year are still high. Pregnant women in Bangetayu Health Center from January to May 2018 who experience Chronic Energy Deficiency (CED) are 73 people (24,3\%), while who experience anemia as many as 103 people $(34,3 \%)$. The population in this study were pregnant women who were enrolled in poly KIA in mid-July to the end of July 2018. The samples were taken in total incidental for one week as many as 53 people and purposive sampling in Bangetayu Kulon village as many as 26 people. Data were collected through questionnaires on rapid nutritional
\end{abstract}


epidemiology surveis and from all samples whose data can be processed only as many as 45 questionnaires. From the processing, the number of occurrences of anemia (moderate and mild anemia) was $71.1 \%$ and CED was $28.9 \%$. Knowledge of Blood-Adding Tablets $46.7 \%$ is good, the level of adherence to taking Blood-Adding Tablets $55.6 \%$ is non-compliant, Respondents who answered that there was no recommended food during pregnancy were $53.3 \%$ and the portion of food was remain and less as much $55.6 \%$.

\section{Keywords: Rapid Survei, CED Pregnant Women, Anemia, Incident}

\section{PENDAHULUAN}

Kekurangan zat besi adalah keadaan defisiensi yang paling umum di dunia, mempengaruhi lebih dari 2 miliar orang secara global.Meskipun hal ini sangat umum di negara-negara yang kurang maju, tetap menjadi masalah yang signifikan di negara maju, bahkan ketika bentuk kekurangan gizi lainnya sudah hampir dieliminasi (Pavord S, et al, 2012)

Anemia dan Kekurangan Energi Kronik (KEK) pada ibu hamil masih menjadi masalah yang cukup berat di Indonesia. hal ini terkait dengan penyebab Angka Kematian Ibu. Depkes RI dalam Muliawati S (2012) menyebutkan Kematian ibu dapat disebabkan oleh penyebab langsung maupun tidak langsung. Penyebab tak langsung kematian ibu antara lain anemia, Kurang Energi Kronis dan "4 terlalu" (terlalu muda/tua, sering dan banyakk)

Depkes RI menjelaskan bahwa Status gizi ibu hamil merupakansalah satu indikator dalam mengukur status gizi masyarakat. Jika masukan gizi untuk ibu hamil dari makanan tidak seimbang dengan kebutuhan tubuh maka akan terjadi defisiensi zat gizi. Kekurangan zat gizi dan rendahnya derajat kesehatan ibu hamil masih sangat rawan, hal ini ditandai masih tingginya AKI yang disebabkan oleh perdarahan karena anemia gizi dan KEK selama masa kehamilan(Yuliastuti E, 2014)

Masalah dan resiko yang dihadapi ibu dengan kekurangan gizi tidaklah sedikit. Ibu hamil dengan kekurangan gizi dapat mengalami anemia, perdarahan, Berat Badan yang tidak meningkat, persalinan sulit dan lama, prematur, perdarahan setelah persalinan. Kurang gizi juga dapat mempengaruhi pertumbuhan janin dan dapat menimbulkan keguguran, cacat bawaan dan Berat Bayi Lahir Rendah (Irianto K,2014).

Hasil penelitian menunjukkan bahwa KEK pada batas LILA $23,5 \mathrm{~cm}$ belum merupakan resiko untuk melahirkan berat badan lahir rendah (BBLR). Sedangkan ibu hamil dengan KEK pada batas LILA $<23 \mathrm{~cm}$ mempunyai resiko 2 kali untuk melahirkan BBLR dibandingkan dengan ibu yang mempunyai lingkar lengan atas (LILA) lebih dari $23 \mathrm{~cm}$ (Yuliastuti E, 2014)

Perubahan fisiologis dan psikologis pada ibu selama hamil membutuhkan kecukupan gizi yang optimal. Status gizi ibu hamil dipengaruhi oleh berbagai faktor. Faktorfaktor tersebut diantaranya adalah jumlah makanan, beban kerja, pelayanan kesehatan, status kesehatan, pendidikan, absorbsi makanan, paritas dan jarak kelahiran, konsumsi kafein, dan konsumsi tablet besi. Apabila dalam masa kehamilan tingkat status gizinya rendah, maka akan mengakibatkan kehamilan yang beresiko, untuk mengurangi resiko tersebut dapat dilakukan dengan mengidentifikasikan faktor penyebab terjadinya status gizi buruk terutama kurang energikronik(Arisman,2008; Irianto, 2014).

Proporsi ibu hamil dengan KEK di Indonesia berdasarkan Riset Kesehatan Dasar tahun 2010 sebesar 33,5\% meningkat menjadi $38,5 \%$ tahun 2013. Data Dinas Kesehatan Propinsi Jawa Tengah tahun 2010 terdapat 13,91\% ibu hamil dengan KEK. Data dari Dinas Kesehatan Kota Semarang, ibu hamil dengan KEK tahun 2013 sebanyak 1.239, tahun 2014 sebanyak 1.356 dan tahun 2015 sampai September 1.836. Ibu hamil yang mengalami KEK di Puskesmas Bangetayu 
dari bulan Januari sampai Mei tahun 2018 yaitu sebanyak 73 orang,

sementara yang menderita anemia sebanyak 103 orang.

\section{METODE PENELITIAN}

Penelitian ini merupakan penelitian deskriptif jenis survei cepat dengan pendekatan cross sectional (Sulistyaningsih, 2012) untuk menganalisis karakteristik kejadian anemia dan KEK di wilayah kerja Puskesmas Bangetayu Kota Semarang yang dilakukan selama 2 minggu. Waktu pelaksanaan yaitu tanggal 09 hingga 21 Juli 2018.

Polpulasi target survei cepat anemia dan KEK pada ibu hamil adalah seluruh ibu hamil yang memeriksakan kehamilannya ke puskesmas Bangetayu pada bulan Juli dan populasi terjangkau adalah ibu hamil yang memeriksakan diri ke poli KIA Puskesmas Bangetayu pada pertengahan bulan Juli hingga menjelang akhir bulan juli tahun 2018 dan ibu hamil yang terdaftar dalam pantauan kasus KEK dari bulan januari hingga mei tahun 2018, dimana kasus KEK tertinggi yaitu di kelurahan Bangetayu kulon.

Sampel diambil secara total insidental pada minggu ke dua yaitu ibu hamil yang datang ANC ke poli KIA Puskesmas Bangetayu sebanyak 53 orang dan purposive sampling yaitu ibu hamil kelurahan Bangetayu kulon yang tersebar di 11 RW dengan jumlah 26 orang. Survei ini menggunakan quesioner survei cepat epidemiologi gizi. Dari keseluruhan quesioner yang diperoleh yaitu 79 responden.Quesioner yang dapat dilanjutkan ke tahap pengolahan dan analisis data hanya sebanyak 45 quesioner dan selebihnya dropout dikarenakan adanya ketidaklengkapan data. Quesioner ini didukung menggunakan data buku KIA dan hasil pemeriksaan kadar $\mathrm{Hb}$ dari laboratorium Puskesmas serta pemeriksaan Lingkar Lengan atas (LiLA) dengan pitameter.

\section{HASIL PENELITIAN}

Karakteristik Responden dikelompokkan ke dalam faktor eksternal (faktor sosial ekonomi dan pelayanan kesehatan) dan faktor internal serta perilaku makannya (Koes Irianto, 2014). Distribusi karakteristik Responden menurut faktor eksternal dapat dilihat pada tabel1. Karakteristik Responden yang ikut dalam survei ini $80 \%$ memiliki tingkat pendidikan menengah, pendapatan atau penghasilan keluarga $88,9 \%$ di atas Rp.789.000, sebanyak 57,8\% ibu hamil tinggal dengan lebih dari 4 orang anggota keluarga dalam satu rumah dan $62,2 \%$ ibu hamil tidak bekerja. Terkait dengan pelayanan kesehatan sebanyak 75,6\% ibu hamil dengan frekuensi ANC baik, pengetahuan tentang Tablet Tambah Darah 46,7\% baik dan cukup sebanyak 37,8\% dengan tingkat kepatuhan dalam meminum Tablet Tambah Darahnya rendah dimana 55,6\% Responden tidak patuh dalam meminum Tablet Tambah Darah.

Sementara distribusi Responden menurut faktor internal yaitu sebanyak $80 \%$ ibu hamil berusia $20-35$ tahun, $48,9 \%$ sedang hamil trimester III dan $40 \%$ hamil trimester II, sebanyak 73,3\% Responden kehamilan multi (lebih dari 1) dengan jarak kehamilan dengan anak terakhir lebih dari 2 tahun sebanyak $84,8 \%$. Untuk perilaku makan sebanyak 95,6\% Responden tidak mempunyai pantangan makan, Responden yang menjawab tidak ada anjuran makanan tertentu selama kehamilannya sebanyak 53,3\%, hanya 44,4 $\%$ menjawab porsi makan lebih banyak, sebanyak 95,6\% Responden tidak memiliki riwayat sakit lama (kronis), 93, 3\% Responden tidak memiliki riwayat operasi saluran cerna dan $60 \%$ menjawab memiliki riwayat menstruasi teratur. Jumlah Kejadian anemia sebanyak $\quad 57,8 \% \quad$ Responden mengalami anemia ringan dan $13,3 \%$ mengalami anemia berat. Sedangkan Responden yang mengalami KEK sebanyak $28,9 \%$.

\section{Tabel 1. Distribusi Karakteristik Responden Menurut Faktor Eksternal di}


Wilayah Kerja Puskesmas Bangetayu Kota Semarang Tahun 2018

\begin{tabular}{|c|c|c|c|}
\hline \multirow{2}{*}{ No } & \multirow{2}{*}{ Karakteristik } & \multicolumn{2}{|c|}{ Jumlah } \\
\hline & & $\mathrm{n}(45)$ & $(\%)$ \\
\hline \multirow[t]{4}{*}{1} & Tingkat Pendidikan & & \\
\hline & $\begin{array}{c}\text { Tidak dan atau pendidikan } \\
\text { dasar }\end{array}$ & 3 & 6,7 \\
\hline & Pendidikan Menengah & 36 & 80 \\
\hline & Pendidikan Tinggi & 6 & 13,3 \\
\hline \multirow[t]{3}{*}{2} & $\begin{array}{c}\text { Pendapatan Keluarga } \\
\text { Sebulan }\end{array}$ & & \\
\hline & pendapatan $\leq$ Rp 789.000,- & 5 & 11,1 \\
\hline & pendapatan > Rp. 789.000,- & 40 & 88,9 \\
\hline \multirow[t]{3}{*}{3} & $\begin{array}{l}\text { Jumlah anggota Keluarga } \\
\text { dalam } 1 \text { rumah }\end{array}$ & & \\
\hline & $>4$ orang & 19 & 42,2 \\
\hline & $\leq 4$ orang & 26 & 57,8 \\
\hline \multirow[t]{6}{*}{4} & Pekerjaan Ibu & & \\
\hline & Tidak Bekerja & 28 & 62,2 \\
\hline & Pedagang & 1 & 2,2 \\
\hline & Buruh & 6 & 13,3 \\
\hline & Karyawati & 2 & 4,4 \\
\hline & lain-lain & 8 & 17,8 \\
\hline \multirow[t]{4}{*}{5} & Frekuensi ANC & & \\
\hline & Kurang & 6 & 13,3 \\
\hline & Cukup & 5 & 11,1 \\
\hline & Baik & 34 & 75,6 \\
\hline \multirow[t]{4}{*}{6} & $\begin{array}{l}\text { Pengetahuan Tentang } \\
\text { Tablet Tambah Darah }\end{array}$ & & \\
\hline & Kurang & 7 & 15,6 \\
\hline & Cukup & 17 & 37,8 \\
\hline & Baik & 21 & 46,7 \\
\hline \multirow[t]{3}{*}{7} & $\begin{array}{l}\text { Kepatuhan Dalam } \\
\text { Meminum TTD }\end{array}$ & & \\
\hline & Tidak Patuh & 25 & 55,6 \\
\hline & Patuh & 20 & 44,4 \\
\hline & er: Data Primer Terolah & & \\
\hline
\end{tabular}

Tabel 2. Distribusi Responden Menurut Faktor Internal di Wilayah Kerja Puskesmas Bangetayu Kota Semarang Tahun 2018

\begin{tabular}{cccc}
\hline \multirow{2}{*}{ No } & \multirow{2}{*}{ Karakteristik } & \multicolumn{2}{c}{ Jumlah } \\
\cline { 3 - 4 } & Usia Ibu Hamil & & $(\%)$ \\
\hline 1 & $<20$ Tahun & 3 & 6,7 \\
\hline \multirow{3}{*}{$20-35$ Tahun } & 36 & 80 \\
\hline \multirow{3}{*}{$>35$ Tahun } & 6 & 13,3 \\
\hline 2 & Usia Kehamilan & & 11,1 \\
\hline \multirow{3}{*}{ Trimester I } & 5 & 40 \\
\hline & Trimester II & 18 & 48,9 \\
\hline 3 & Trimester III & 22 & 26,7 \\
\hline & Jumlah Kehamilan & &
\end{tabular}

\begin{tabular}{|c|c|c|c|}
\hline & Lebih dari 1 (multi) & 33 & 73,3 \\
\hline \multirow[t]{4}{*}{4} & $\begin{array}{c}\text { Jarak Kehamilan } \\
\text { dengan Anak } \\
\text { Sebelumnya } \\
\end{array}$ & & \\
\hline & $\leq 2$ Tahun & 5 & 11,1 \\
\hline & $>2$ Tahun & 28 & 62,2 \\
\hline & Missing & 12 & 26,7 \\
\hline \multirow[t]{3}{*}{5} & Paritas Ibu & & \\
\hline & $\begin{array}{c}\text { Pernah Melahirkan } \\
\text { Sebelumnya }\end{array}$ & 32 & 71,1 \\
\hline & $\begin{array}{c}\text { Belum Pernah } \\
\text { Melahirkan } \\
\text { Sebelumnya } \\
\end{array}$ & 13 & 28,9 \\
\hline \multirow[t]{3}{*}{6} & Riwayat Abortus & & \\
\hline & Ada & 5 & 11,1 \\
\hline & Tidak ada & 40 & 88,9 \\
\hline
\end{tabular}

Tabel 3. Distribusi Responden Berdasarkan Perilaku Makan dan Riwayat Medis Di Wilayah Kerja Puskesmas Bangetayu Kota Semarang Tahun 2018

\begin{tabular}{|c|c|c|c|}
\hline \multirow{2}{*}{ No } & \multirow{2}{*}{ Karakteristik } & \multicolumn{2}{|c|}{ Jumlah } \\
\hline & & $\mathrm{n}(45)$ & $(\%)$ \\
\hline \multirow{8}{*}{1} & Pantangan & & \\
\hline & Makan selama & & \\
\hline & hamil & & \\
\hline & $\mathrm{Ya}$ & 2 & 4,4 \\
\hline & Tidak & 43 & 95,6 \\
\hline & $\begin{array}{c}\text { Tertentu } \\
\text { selama hamil }\end{array}$ & & \\
\hline & Tidak Ada & 24 & 53,3 \\
\hline & Ada & 21 & 46,7 \\
\hline \multirow[t]{4}{*}{3} & $\begin{array}{c}\text { Porsi Makan } \\
\text { Ibu Selama } \\
\text { Hamil } \\
\end{array}$ & & \\
\hline & Lebih sedikit & 7 & 15,6 \\
\hline & Tetap & 18 & 40 \\
\hline & Lebih Banyak & 20 & 44,4 \\
\hline \multirow[t]{3}{*}{4} & $\begin{array}{l}\text { Riwayat Sakit } \\
\text { lama }\end{array}$ & & \\
\hline & $\mathrm{Ya}$ & 2 & 4,4 \\
\hline & Tidak & 43 & 95,6 \\
\hline 5 & $\begin{array}{c}\text { Riwayat } \\
\text { Operasi saluran } \\
\text { Cerna } \\
\end{array}$ & & \\
\hline & $\mathrm{Ya}$ & 3 & 6,7 \\
\hline & Tidak & 42 & 93,3 \\
\hline 6 & $\begin{array}{c}\text { Riwayat } \\
\text { Menstruasi } \\
\text { Teratur }\end{array}$ & & \\
\hline & $\mathrm{Ya}$ & 27 & 60 \\
\hline & Tidak & 18 & 40 \\
\hline
\end{tabular}

Sumber: Data Primer Terolah 
Tabel 4. Jumlah Kejadian Anemia dan KEK pada Ibu Hamil di Wilayah Kerja Puskesmas Bangetayu Kota Semarang Tahun 2018.

\begin{tabular}{|c|c|c|c|}
\hline \multirow{2}{*}{ No } & \multirow{2}{*}{ Karakteristik } & \multicolumn{2}{|c|}{ Jumlah } \\
\hline & & $\mathrm{n}(45)$ & $(\%)$ \\
\hline \multirow{7}{*}{1} & Klasifikasi Anemia & & \\
\hline & Berdasarkan $\mathrm{Hb}$ & & \\
\hline & dan Klinis & & \\
\hline & Anemia Sedang & 6 & 13,3 \\
\hline & Anemia Ringan & 26 & 57,8 \\
\hline & Normal & 12 & 26,7 \\
\hline & Missing & 1 & 2,2 \\
\hline \multirow{4}{*}{2} & Klasifikasi KEK & & \\
\hline & berdasarkan LiLA & & \\
\hline & KEK & 13 & 28,9 \\
\hline & Tidak KEK & 32 & 71,1 \\
\hline & $\begin{array}{l}\text { Aber: Data Primer } \\
\text { terolah }\end{array}$ & & \\
\hline
\end{tabular}

\section{PEMBAHASAN}

Penelitian ini menggunakan quesioner survei cepat epidemiologi gizi ibu hamil Anemia dan KEK sehingga tidak dilakukan uji validitas dan reliabilitas sebelum digunakan (Suparyanto, 2010; Sulistyaningsih, 2012), namun setelah digunakan dan diberikan kepada Responden untuk dijawab terdapat beberapa pertanyaan yang Responden agak kesulitan untuk memahaminya sehingga peneliti sekaligus pewawancara memberikan penjelasan ulang. Selain itu pengisian quesioner dalam survei ini juga dilakukan bertepatan dengan pelayanan ante natal care sehingga waktu pengisian kurang efektif.

Berdasarkan hasil yang diperoleh dari pengolahan data bahwa ada data yang cukup mencolok dari faktor eksternal yaitu adanya sedikit kontradiktif antara tingkat pengetahuan ibu tentang Tablet Tambah Darah dengan kepatuhan dalam meminumnya. berdasarkan data tersebut tingkat pengetahuan Responden cukup dan baik mencapai $84,5 \%$, sementara tingkat kepatuhan dalam meminum Tablet Tambah Darah masih dibawah 50\% (44,4\%). Iniartinya tingkat pengetahuan yang cukup bahkan baik tentang Tablet Tambah darah belum dapat memastikan seorang ibu hamil akan patuh dalam meminum Tablet Tambah

Darah. Green dan kreuter (1991) dalam teorinya, menjelaskan bahwa peningkatan pengetahuan seseorang tidak selalu menyebabkan perubahan perilaku. Perubahan perilaku dipengaruhi oleh berbagai faktor yaitu predisposing, enabling dan reinforcing. Namun demikian, Handayani S dan Budianingrum S (2011) dalam penelitiannya menyebutkan bahwa pengetahuan merupakan variabel yang berpengaruh bermakna terhadap kejadian KEK. Terkait hal inipun perlu kajian yang lebih mendalam mengenai kualitas pengetahuan ibu hamil tentang pentingnya Tablet Tambah Darah, Bagaimana sikap dan Perilaku terkait Kepatuhan dalam meminumnya.

Ada banyak alasan untuk respon yang tidak adekuat terhadap terapi besi oral termasuk ketidakpatuhan (paling umum), dosis yang tidak memadai, penyerapan yang tidak memadai (misalnya karena penyakit radang usus atau celiac), kerugian berkelanjutan yang melebihi penyerapan (hilangnya gastrointestinal okultisme atau Heavy Menstrual Bleeding (HMB) tidak dikelola) atau diagnosis yang salah (Percy L dan Mansour D, 2016). Suplementasi zat besi oral adalah lini pertama dalam manajemen Defisiensi Besi / Anemia defisiensi Besi karena murah dan efektif, jika diambil dengan tepat. Ada banyak produk dan persiapan yang tersedia. Disarankan bahwa orang dewasa, termasuk wanita hamil, menelan 100-200 mg zat besi setiap hari dalam 2 sampai 3 dosis terbagi untuk pengobatan Anemia Defesiensi Besi dan $65 \mathrm{mg}$ setiap hari untuk mereka yang berisiko Defesiensi Besi (Pasricha SR, et al, 2010). Selain itu dari faktor perilaku makan terlihat bahwa sebanyak 53,3\% Responden menjawab tidak ada anjuran makanan tertentu selama hamil ditambah lagi porsi makan selama hamil tidak berubah (tetap) dibandingkan sebelum hamil yaitu sebanyak 40\%, dan bahkan 15,6\% Responden menjawab porsi makan menjadi lebih sedikit. Hal ini dapat dikaitkan dengan pola makan sebelum hamil 
atau masa pra nikah dan ketidaknyamanan serta keluhan berkaitan dengan perubahan fisiologis selama masa kehamilan.

Mahirawati (2014) menyebutkan bahwa Sosialisasi informasi mengenai kesiapan fisik dan psikologis diprioritaskan kepada kaum remaja putri, agar saat memasuki masa pernikahan sudah mempunyai bekal ilmu dan wawasan serta kesehatan reproduksi yang sudah siap menghindari risiko kejadian KEK dan anemia serta masalah kesehatan lain yang berkaitan dengan proses kehamilan dan persalinan. Upaya yang perlu dilakukan untuk menurunkan prevalensi anemia di masyarakat yaitu melakukan peningkatan Kuantitas dan kualitas pelayanan ANC, upaya deteksi dini faktor risiko lebih diperhatikan, pelayanan didasarkan pada SOP sesuai ketentuan dan peningkatan Kuantitas dan kualitas TTD. (Wibowo Y, Wisnuwijoyo AP, 2014).

\section{KESIMPULAN}

Jumlah Kejadian Anemia (anemia sedang dan ringan) sebesar $71,1 \%$ dan KEK sebesar 28,9\% dengan karakteristik Responden yaitu pengetahuan tentang Tablet Tambah Darah 46,7\% baik, 37,8\% cukup dan tingkat pengetahuan kurang hanya 15,6\%.Tingkat kepatuhan dalam meminum Tablet Tambah Darah cukup rendah dimana 55,6\% Responden tidak patuh, Responden yang menjawab tidak ada anjuran makanan tertentu selama hamil sebanyak 53,3\% dan porsi makan tetap dan lebih sedikit sebanyak $55,6 \%$. Beberapa hal yang memungkinkankan dan melatar belakangi tingginya kejadian anemia dan KEK adalah rendahnya kepatuhan Responden dalam meminum TTD dan perilaku makan yang dikaitkan dengan tidak adanya anjuran makanan tertentu serta porsi makan yang tidak berubah bahkan lebih sedikit selama hamil.

\section{SARAN}

Upaya penurunan Jumlah Kejadian Anemia dan KEK pada ibu hamil perlu mempertimbangkan adanya peningkatan kualitas ANC terkait Pendidikan kesehatan terutama tentang TTD dan pentingnya pemenuhan gizi yang sesuai selama masa kehamilan, perlu adanya pemantauan jumlah TTD yang diminum oleh Ibu hamil oleh petugas serta deteksi dini anemia dan KEK sejak masa pra nikah.

\section{DAFTAR PUSTAKA}

Arisman. (2007). Gizi Dalam Daur Kehidupan. Jakarta: EGC

YuliastutiE. (2014). Faktor-Faktor yang Berhubungan Dengan Kekurangan Energi Kronis Pada Ibu Hamil Di Wilayah Kerja Puskesmas Sungai Bilu Banjarmasin, An Nadaa, Vol 1 No. 2, desember 2014, hal 72-76

Green LW \& Kreuter. (1991). Health Promotion Planning An Educational and Environmental Approach. 2, editor. toronto london: Mayfield Publising Company.

Irianto K. (2014). Gizi Seimbang Dalam Kesehatan reproduksi Balanced Nutrition In Reproduvtive Health. Bandung: Alfabeta

ParichaS-R.S.,Flecknoe-

Brown,S.C.,Allen,K.J.,etal

(2010).

Diagnosisand

managementofirondeficiencyanaemia:a

clinicalupdate.Med J Aust.2010 Nov 1; 193 (9): 525-32.

Pavord,S.,Myers,B.,Robinson,S.etal. (2012).UKguidelinesonthemanagement ofirondeficiencyinpregnancy.BrJHaemat ol156:588-600

Percy L dan Mansour D (2016). Iron deficiency and iron deficiency anaemia in women's health, Best Practice \& Research Clinical Obstetrics \& Gynaecology, doi: 10.1016/j.bpobgyn.2016.09.007

Riset Kesehatan Dasar (Riskesdas) 2013, Badan Penelitian dan Pengembangan Kesehatan Kementerian Kesehatan RI Tahun 2013

Sastroasmoro S dan Ismael S. (2014). DasarDasar Metodologi Penelitian Klinis. 
Jakarta: CV Sagung Seto

Handayani S dan Budianingrum S. (2011). Analisis Faktor-faktor Yang Mempengaruhi Kekurangan Energi Kronis Pada Ibu Hamil Di Wilayah Puskesmas Wedi Klaten, Jurnal Involusi Kebidanan, Vol i, No 1, Januari 2011, 4260

Sulistyaningsih. (2012). Metodologi Penelitian Kebidanan KuantitatifQualitatif, Yogyakarta: Grahailmu

Mahirawati VK. (2014). Faktor-faktor yang Berhubungan Dengan Kekurangan Energi Kronis (KEK) pada Ibu Hamil di Kecamatan Kamoning dan Tambelangan, Kabupaten Sampang Jawa Timur, Pusat Humaniora Kebijakan Kesehatan dan Pemberdayaan Masyarakat, Litbang Kesehatan Kemenkes RI

Wibowo Y, Wisnuwijoyo AP. (2014). Survei Cepat: Karakteristik \& Prevalensi Anemia Ibu Hamil Di Kabupaten Sukoharjo Tahun 2011, Mandala Of Health Volume 7, Nomor 3, September 2014

Suparyanto. (2010). Uji Validitas dan Reliabilitas. $\mathrm{http}: / / \mathrm{dr}-$ suparyanto.blogspot.com/2010/12/ujivaliditas-kuesioner-penelitian.html 